In another series of experiments, in place of the black cardboand was substituted another cardboard with an adjustable diaphragm which entirely concealed the white background except so much as could be seen through the diaphragm. If now the opening remained unchanged in distance but was made smaller or larger, the observer obtained the impression of an increase or decrease in distance, although accommodation and convergence did not alter. If the cardboard was moved nearer, and the opening at the same time was more than proportionally diminished, then in spite of increasing strain of accommodation the observer believed that the object had been moved farther away.

From these results Dr. Hillebrand concludes that accommodation and convergence, when thus isolated, give us no information in regard to the distance of the point of fixation; in other words, that 'so-called muscle-sensations' have no existence, or at least have no importance in visual localization. Without them it is easy to explain the results mentioned under (2) above, on the supposition that when the change in distance is sudden the observer voluntarily changes his accommodation, and knows, since it is voluntary, whether the new accommodation is for a nearer or farther object; and hence knows also whether the object has moved nearer or farther away, because if his first change of accommodation has not succeeded in making the image of the object clearer, a second change in the opposite direction will do so. When, however, the change in accommodation is involuntary, as in the experiments under ( $\mathrm{r}$ ), there is no means of knowing the direction or even the fact of movement, since, as these experiments establish, the changes in accommodation and the always accompanying changes in convergence yield no muscle-sensations to reveal the nature or the existence of these changes.

E. B. Delabarre.

Brown UNIVIrasty.

\title{
ASSOCIATION, REACTION.
}

Minor Studies from the Psychological Laboratory of Cornell University. Communicated by E. B. Titchener. I. 'Mediate' Association. H. C. Howe. II. 'Sensorial' and 'Muscular' Reattions. A. R. Hruz and R. Watanabe. Am. Jour. of Psychol, vi. 239-246. Jan. $x 894$.

-Professor Titchener contributes the first-fruits of the Psychological Laboratory of Cornell University, from which much admirable work in experimental psychology may be expected. Mediate association and sensory and muscular reactions seem to be receiving more than their due share of attention just now, but these experiments are presented in a concise form which should serve as a model. 
Mr. Howe repeated and varied Dr. Scripture's experiment on mediate or subconscious association, and found (as Prof. Münsterberg had previously found) that he could not confirm Dr. Scripture's results. Dr. Scripture's experiment consisted in presenting for a short time words with obscure signs, which latter the observer was supposed not to notice distinctly nor remember. When one of the words was presented a second time, a word having the same sign was likely to recur. The present writer remarked in $M$ ind some years ago that subconscious association seems to play an important part in the sequence of ideas. When an observer is asked to name the first word suggested by a given word, the word actually named seems often to be connected with the original word by links which are not given in distinct consciousness. But the process is one difficult to observe or to study by experiments which are unambiguous.

Messrs. Hill and Watanabe made experiments on sensory and motor reactions in which the movement was made with the lips and with the closed thumb and index-finger. They found the distinction to obtain in these cases as well as when the movement was made in the usual fashion. The Wundt controlling hammer was out of order, and the times and differences are said not to be absolute, but in most cases the sensory times were $78-155 \sigma$ longer than the motor times. With some of the observers a distinction between motor and sensory reactions could not be found and the writers conclude that "not every person is able to function as a reaction-subject. Rather is there required for the work a special kind of mental disposition or Anlage." The present writer does not consider the interpretation of motor and sensory reactions given by Professor Wundt and Dr. Lange as valid, but-as the President of the University from which these studies come has remarked -a man has before this gone out to look for asses and found a kingdom. In the manner suggested independently by Professor Floumoy and Professor Baldwin the attitude of the subject in reacting may throw light on the important distinction between visual, auditory, and motor 'types.'

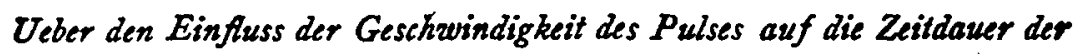
Reactionszeit bei Schalleindrücken. J. J. van Biervliet. Philom. Stud., X. 160-167. 1894 .

Professor van Biervliet describes with unusual clearness experiments. made with unusual exactness on the relation between the rate of the pulse and the length of the reaction-time. In the case of to of the II observers the reaction-time tended to become shorter as the pulse was quicker. Thus with one observer the following results were obtained: 


\begin{tabular}{|c|c|c|c|}
\hline Pulse & $\begin{array}{l}70 \text { to } \\
80\end{array}$ & $\begin{array}{l}80 \\
90\end{array}$ & 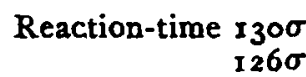 \\
\hline & 90 & 100 & $121 \sigma$ \\
\hline & 100 & 110 & $1 \times 7 \sigma$ \\
\hline
\end{tabular}

In other cases there is less regularity, but the number of experiments and careful methods justify the conclusion that "in general the reaction-time for sound is lessened as the rate of the pulse increases." The reactions were 'sensory,' but the times and their variability are about normal, and it does not seem possible that they could be much reduced by directing the observer to make the reactions 'motor.' These II observers and the 8 tested by Dr. Dessoir must be counted among those who have not the Anlage necessary for experiments on sensory and motor reactions.

Mediate Association. W. G. Smith. Mind, N. S. III. 289-304. July, 1894 .

The first place in the July No. of Mind is given to experiments made by Dr. Smith at Leipzig and used in an inaugural dissertation. Dr. Scripture's experiments were once more repeated, and a variation was introduced by partly menorizing the series. The result may be readily summed up in the words of the author. "Münsterberg's results were entirely negative; so are those of the present research." While Dr. Smith's paper does not contain any important advance in expenmental method, the discussion is timely and interesting. The connection of non-contiguous terms in a series which makes it easier to learn the alternate terms when the whole series has been previously memorized (Ebbinghaus) is attributed to motor activity, and Hume's reference to indirect association is quoted and criticised. We may expect further experiments on mediate association from the Yale Laboratory which will clear up discrepancies between Dr. Scripture's original experiments and the results of later investigations.

Ein Beispiel von Association durch unbewusste Mittelglieder. Dr. W. JrRusalex. Philos. Stud., X. 323-328. 2894.

Sind die Mittelglieder einer Mittelbaren Assaciation bewusst oder unberussst \& W. WuNDT. Philos. Stud., X. 326-328. 1894.

Dr. Jerusalem reperts a case given him by a careful observer. The observer, immersed in work, suddenly saw in imagination a scene of which he had not thought for many years. Tracing the cause he found it to be the unnoticed fragrance of a fiower in the room, which flower had been part of the original scene. 
Professor Wundt adds a note to this observation in which he argues that the smell of the flower was unnoticed but not unconscious-it was perceived but not 'apperceived.'

J. McK. C.

\section{PLEASURE AND PAIN.}

The Psychological Analysis and Physical Basis of Pleasure and Pain. Lightrer WituER. The Journal of Nervous and Mental Disease, April 1894, pp. 209-228.

In view of the prevalence of the theory that pleasure and pain are qualities attributable to all states, but not themselves independent sensations, and especially in view of Mr. Marshall's presentation of this theory, Dr. Witmer shows that this is not the most simple and intelligible doctrine, nor that to which the latest discoveries in physiology point. Our current classifications, that of the five senses, for instance, are not founded primarily on introspection or upon the arrangement of feeling accordings to their in ward similarity, but rather these classications are based on psycho-physical observation, that is, they are groupings of sensations according to the identity of their organs or the continuity of their known external causes. This is the case with heat and cold, and with pleasure and pain. Thus the definition of a sensation may be psycho-physical or introspective; it may mean the whole mental effect of exciting a peripheral organ or it may mean the simplest unanalyzable element of consciousness. Now in both senses pleasure and pain are probably sensations: in the former, because recent discoveries show the existence of pain-nerves and suggest the possibility of nerves for pleasure ; in the latter, because in cases of extreme pleasure or pain there is hardly any image present, and because, most perceptions being very complex, the existence of pain or pleasure as elements in them is perfectly compatible with the essential independence of these elements.

G. Santayana.

Hartaro UNTVERSTTY.

\section{EMOTION.}

Recherches sur les rapports de la sensibilite et de l'emotion. P. SolLirr. Revue Philosophique, XXXvII. 241-266. 1894.

Prof. James' Theory of Emotion. D. IRons. Mind; N. S. III. 77-97. 1894.

Both the above articles deal with James' theory of emotion. The first seeks to confirm it by experimental evidence, the latter subjects it to a searching and, in the author's judgment, annihilating criticism. 